\section{Virus Diseases}

Edited by R. B. Heath. Pp. $x+144$, illustrated. Pitman Medical, London, 1979. £9.50.

This book results from a conference held at the Royal College of Physicians in London and the brief for the organization of the conference and the book was that it should be 'virology for physicians' and not 'virology for virologists'. I am sure that it will be well received by clinicians, but I suspect that it will also be found on the bookshelves of clinical virologists and possibly medical students.

An important function of a reviewer is to assess the value of a particular volume for people who may not be able to inspect a copy before they purchase. It should be pointed out that anybody attracted by the contents list of authors and subjects may be disappointed in opening the book. Three of the 14 chapters are extremely brief-namely those on subacute schlerosing panencephalitis, the viral aetiology of cancer, and retroviruses. One of these 'chapters' is in fact no more than a list of 5 of the author's recent publications and another is an abstract prepared for the paper which was presented at the meeting.

Fortunately other chapters in the book are of considerable value and will be welcomed as readable 'updates' in important topical areas of clinical virology. The sections on Viral Hepatitis, by J. R. Pattison and A. J. Zuckerman; Diabetes, by A. G. Cudworth; and Rabies Prevention in the U.K. by Sylvia Gardner; are particularly impressive. This last account contains some most interesting historical data.

Most chapters include a useful reference list and the illustrations are of reasonable quality and value. Despite its shortcomings, the book can be recommended to those with an interest in viruses and human disease. 